\title{
Hot Tensile Behaviors and Microstructure Evolution of Ti-6Al-4V Titanium Alloy Under Electropulsing
}

\author{
Dong-Wei Ao ${ }^{1} \cdot$ Xing-Rong Chu ${ }^{1} \cdot$ Shu-Xia Lin $^{1} \cdot$ Yang Yang $^{2} \cdot$ Jun Gao $^{1}$ \\ Received: 3 January 2018/Revised: 6 February 2018/Published online: 16 May 2018 \\ (C) The Chinese Society for Metals and Springer-Verlag GmbH Germany, part of Springer Nature 2018
}

\begin{abstract}
The effect of electropulsing on the mechanical behaviors and microstructures of Ti-6Al-4V titanium alloy was investigated by an uniaxial tensile test. Compared to the value measured in cold tensile test, the alloy exhibits lower ultimate tensile strength when the tensile deformation is assisted by electropulsing. The tensile elongation is found to vary non-monotonically with increasing root mean square (RMS) current density. Though decreasing at first, the tensile elongation increases with current density once the value exceeds $8.1 \mathrm{~A} / \mathrm{mm}^{2}$. Through applying current with RMS current density of $12.7 \mathrm{~A} / \mathrm{mm}^{2}$, the tensile elongation at strain rate $0.001 \mathrm{~s}^{-1}$ can be improved by $94.1 \%$. In addition, it is observed that more remarkable electroplastic effect is induced by the higher peak current density under similar thermal effect. Microstructure analysis reveals that the low plasticity at $8.1 \mathrm{~A} / \mathrm{mm}^{2}$ is attributed to the micro-void easily formation near the tips of acicular $\beta$ phases. The enhanced ductility at higher current densities, on the other hand, is attributed to the dynamic recrystallization.
\end{abstract}

Keywords Ti-6Al-4V alloy $\cdot$ Electropulsing $\cdot$ Mechanical properties $\cdot$ Microstructure $\cdot$ Fracture morphology

\section{Introduction}

Because of its low density, high specific strength, and high corrosion resistance, Ti-6Al-4V alloy has good potential in many industrial fields such as aerospace and shipbuilding [1-3]. The alloy usually has to be fabricated at high temperatures due to its low formability at ambient temperature. Through applying heat treatment with temperature above $930{ }^{\circ} \mathrm{C}$, Guo et al. [4] investigated the influence of microstructure on mechanical properties of Ti-6Al-4V alloy. The results indicated that the microstructure could be adjusted by the conventional heating, which had an important effect on the property of Ti-6Al-4V alloys.

Available online at http://link.springer.com/journal/40195.

Jun Gao

shdgj@sdu.edu.cn

1 Associated Engineering Research Center of Mechanics and Mechatronic Equipment, Shandong University, Weihai 264209, China

2 A Key Laboratory of Optoelectronic Materials Chemistry and Physics, Fujian Institute of Research on the Structure of Matter, Chinese Academy of Science, Fuzhou 350002, China
However, this brings about many problems, such as low efficiency and high-energy consumption, due to the repeated and prolonged conventional heating.

Recently, some researchers started to apply electropulsing on the alloys during process, trying to replace the conventional heating. In addition to the works by Kim et al. [5], which reported that the plasticity of an alloy sheet could be improved by simply using an electric current during deformation, the classic studies of Roh et al. [6] provide a background knowledge regarding sheet metal forming technique using electroplasticity. Ye et al. [7] indicated that dynamic recrystallization (DRX) of Ti-6Al$4 \mathrm{~V}$ alloy and micro-cracks healing occurred at a relative low temperature during electropulsing rolling process. Zhou et al. [8] performed cold drawing of the Ti-6Al-4V alloy under electropulsing. It is found that the electropulsing could promote the deformation and the homogeneous deformation microstructure was obtained. Li et al. [9] investigated the effect of grain size on thermal and mechanical properties of Ti-6Al-4V alloy under electrically assisted tensile test, and the results indicated that pulsed current could promote the dislocation motion and decrease the flow stress. Song et al. [10] carried out electropulsing treatment on deformation of Ti-6Al-4V alloy. It 
was observed that the flow stress was decreased by $17.6 \%$ and the elongation was increased by $35 \%$. The phenomenon that the reduction of flow stress and the improvement of plasticity induced by electropulsing are named electroplastic (EP) effect $[11,12]$. EP effect was first reported by Troiskii in 1963 [13]. Subsequently, extensive studies about EP effect were carried out by Troiskii and Conrad [11, 14-16]. In general, the scholars classify electroplastic effect into thermal and athermal effect $[17,18]$. To investigate the mechanisms of EP effect on deformation behaviors of Ti-6Al-4V alloy, Tang and coworks [19] conducted electropulsing rolling Ti-6Al-4V alloy, and the results suggested that the influence of electropulsing on the microstructure and mechanical behavior could not be solely regarded as a consequence of the thermal effects. Ye et al. [20] investigated the effect of electropulsing on the microstructure of Ti-6Al-4V alloy. The results showed that electropulsing could accelerate phase transformation more effectively due to athermal effect, compared with the conventional heat treatment at the same temperature. However, some studies questioned about the mechanism of electropulsing whether athermal effect exists in Ti-6Al-4V alloys, since EP effect may be a material dependent phenomenon [21]. Kisney et al. [22] proposed that the electric current only had thermal effect during tensile deformation of Ti-6Al-4V alloy. Similarly, Magaree et al. [23] pointed out that stress reduction was not observed under electrically assisted titanium alloy tensile test, compared to the conventional tensile test. Therefore, for electrically assisted deformation of Ti-6Al$4 \mathrm{~V}$ alloy, the mechanism of EP effect, especially the existence of athermal effect, is still of debate.

In this work, the uniaxial tensile test was conducted by controlling variable electropulsing parameters with frequency range of $0-450 \mathrm{~Hz}$ and peak current density of $103.9-186.7 \mathrm{~A} / \mathrm{mm}^{2}$. The mechanical properties and microstructure were systematically investigated, aiming at investigating: (1) the influence of EP effect on the mechanical property and microstructure; (2) the existence of athermal effect of Ti-6Al-4V alloy.

\section{Experimental}

The experimental material is a hot-rolled Ti-6Al-4V sheet. The microstructure of as-received Ti-6Al-4V alloy is shown in Fig. 1. The chemical composition of the Ti-6Al$4 \mathrm{~V}$ alloy is listed in Table 1 . The flat dog-bone specimens with a rectangular cross section of $0.7 \mathrm{~mm} \times 6 \mathrm{~mm}$ and a gauge length of $10 \mathrm{~mm}$ were machined along the rolling direction by a laser cut machine.

The uniaxial tension tests under electropulsing were implemented by a self-build experimental set-up, as shown

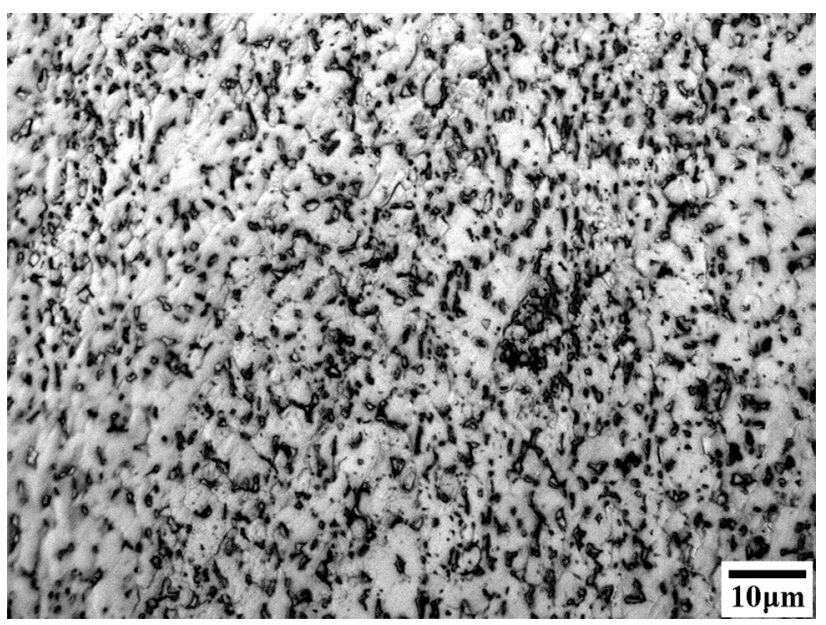

Fig. 1 Optical micrograph of as-received specimens

Table 1 Chemical compositions of the Ti6Al4V sheet specimens (wt\%)

\begin{tabular}{llllllll}
\hline Al & $\mathrm{V}$ & $\mathrm{Fe}$ & $\mathrm{C}$ & $\mathrm{O}$ & $\mathrm{N}$ & $\mathrm{H}$ & $\mathrm{Ti}$ \\
\hline 6.0 & 4.1 & 0.19 & 0.02 & 0.16 & 0.02 & 0.002 & Bal. \\
\hline
\end{tabular}

in Fig. 2a. Special clamps insulated by Bakelite could protect the CMT-5305 universal testing machine from electropulsing. It was assured that the electric current can just flow through the specimens. Electropulsing was applied by a THDM-1 electropulsing generator with a maximum output of 5000 A during tensile process. The waveform of electropulsing is shown in Fig. $2 \mathrm{~b}$ and the specimens were periodically affected by high-energy sine wave with a short pulse duration $(62-64 \mu \mathrm{s})$. The factor $\left(t_{\mathrm{i}} / t_{\mathrm{p}}\right)$ was the pulsewidth ratio for each pulse wave as the period $\left(t_{\mathrm{p}}\right)$ was obtained by the equation $t_{\mathrm{p}}=1 / f$. The pulse-width ratio $\left(t_{\mathrm{i}} / t_{p}\right)$ enhances with the frequency $(f)$ of electropulsing. During this test, the peak current depended on output voltage, and RMS current was obtained by adjusting the voltage and frequency. RMS current values represent the integrated electric-thermal energy through specimens, leading to the Joule heating effect. In this study, the current density was defined as the initial current density as a ratio of the constant electric current to the initial cross-sectional area during each test. The experimental parameters including electropulsing parameters and strain rates are listed in Table 2. In addition to the 12 different sets of electropulsing parameters in group I, two sets of electropulsing parameters were applied as listed for group II in Table 2. The set of electropulsing parameters, $J_{\mathrm{p}}=169.5 \mathrm{~A} / \mathrm{mm}^{2}$ and $J_{\mathrm{p}}=186.7 \mathrm{~A} / \mathrm{mm}^{2}$, which was adjusted to obtain similar RMS current density of $J_{\mathrm{p}}=103.9 \mathrm{~A} / \mathrm{mm}^{2}$, respectively, were applied to study the impact of peak current density on the mechanical property. 

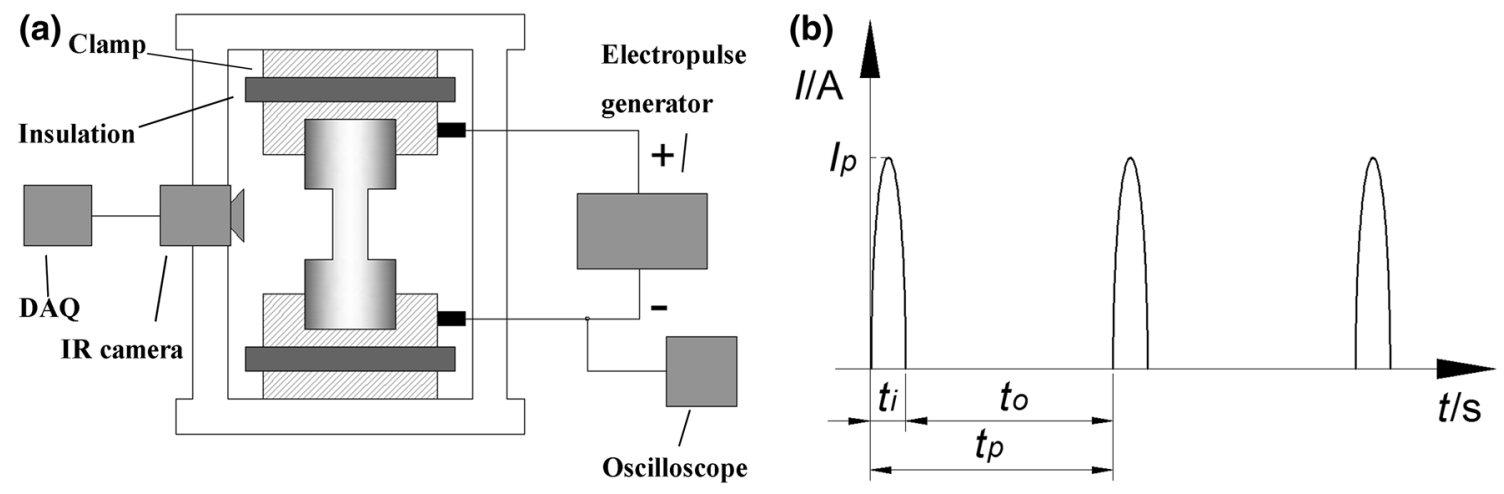

Fig. 2 a Experimental set-up; b waveform of electropulsing ( $t_{\mathrm{i}}$ is pulse duration, $t_{\mathrm{o}}$ is pulse interval, $I_{\mathrm{p}}$ is peak current, $t_{\mathrm{p}}$ is period)

Table 2 Experimental parameters

\begin{tabular}{|c|c|c|c|c|c|c|c|}
\hline & \multirow[t]{2}{*}{ Strain rates $\left(\mathrm{s}^{-1}\right)$} & \multicolumn{6}{|c|}{ Electropulsing parameters } \\
\hline & & Voltage (V) & Frequency (Hz) & Duration $(\mu s)$ & $\begin{array}{l}J_{\mathrm{r}} \\
\left(\mathrm{A} / \mathrm{mm}^{-2}\right)\end{array}$ & $\begin{array}{l}J_{\mathrm{p}} \\
\left(\mathrm{A} / \mathrm{mm}^{-2}\right)\end{array}$ & $t_{\mathrm{i}} / t_{\mathrm{p}}$ \\
\hline \multirow[t]{4}{*}{ Group I } & 0.010 & 20 & 150 & 64.0 & 8.1 & 103.9 & 0.0096 \\
\hline & 0.005 & 20 & 250 & 62.8 & 10.0 & 103.9 & 0.0157 \\
\hline & 0.001 & 20 & 350 & 63.5 & 11.6 & 103.9 & 0.0222 \\
\hline & & 20 & 450 & 62.4 & 12.7 & 103.9 & 0.0281 \\
\hline \multirow[t]{2}{*}{ Group II } & 0.005 & 28 & 135 & 62.0 & 11.1 & 169.5 & 0.0084 \\
\hline & & 30 & 130 & 62.4 & 12.5 & 186.7 & 0.0081 \\
\hline
\end{tabular}

$J_{\mathrm{r}}$ represents RMS current density; $J_{\mathrm{p}}$ represents peak current density

The tensile tests were repeated three times under each deformation condition.

The thermal effect was measured by optris PI infrared thermal imaging (IR) camera. To improve the accuracy, the IR camera was calibrated with a TES1310 K thermocouple. The electrical parameters such as the frequency, RMS current, peak current, and duration were collected by Hall sensor and Tektronix TDS 1002 C-EDU oscilloscope. The specimens were polished and etched by kroll solution (30\% HF 1-3 ml, 65\% $\mathrm{HNO}_{3} 2-6 \mathrm{ml}$, distilled water $100 \mathrm{ml}$ ). Axio Lab A1 optical microscope (OM) and Nova NanoSEM 450 scanning electron microscope (SEM) were applied to analyze the microstructures and fracture surface, respectively. The phase composition of the specimens was analyzed by $\mathrm{X}$-ray diffraction (XRD) with $\mathrm{Cu} K \alpha$ radiation (40 V/200 mA).

\section{Results}

\subsection{Joule Heating Effect Under Electropulsing}

The electro-thermal temperature was uniformly distributed in the gauge area with the maximum temperature occurring at the center of specimens due to the necking of tensile in Fig. 3a [24]. In the following work, the vicinity of gauge area in the center of specimen is employed to characterize the Joule heating effect in the EPT tests [25]. Figure 3b presents that temperature rises with RMS current density at the strain rate of $0.005 \mathrm{~s}^{-1}$. It is shown that the temperature increases with the deformation time, due to the accumulation of Joule heating. The temperature evolution is related with specimen necking; it rises almost linearly until necking, as shown in Fig. 3c. The temperatures continue to rise after necking. This is mainly because that the reduction of cross-sectional area leads to the high RMS current density $[24,25]$. The maximum temperature evolution with RMS current density and strain rates is shown in Fig. 3d. It is found that the maximum temperature at each strain rate increases with the RMS current density. According to adiabatic Eq. (1) [26], the temperature is direct proportional to RMS current density. The higher RMS current density contributes to the larger Joule heating effect. In addition, the heating time rises with the reduction of strain rate, causing an increasing Joule heating effect, which agrees with the observed results, as shown in Fig. 3d:

$\partial \Delta T / \partial t=\left(I_{\mathrm{r}} / S\right)^{2} \gamma / C \rho$, 
(a)

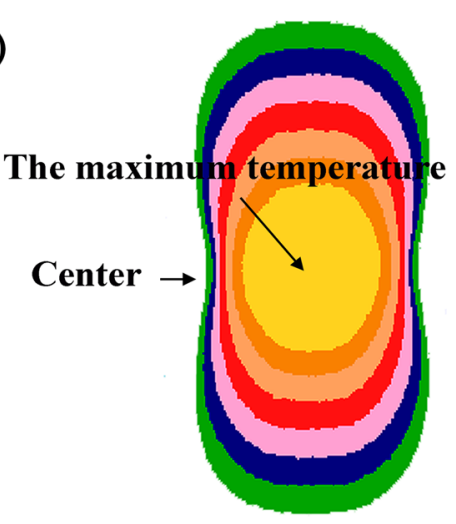

1210

676
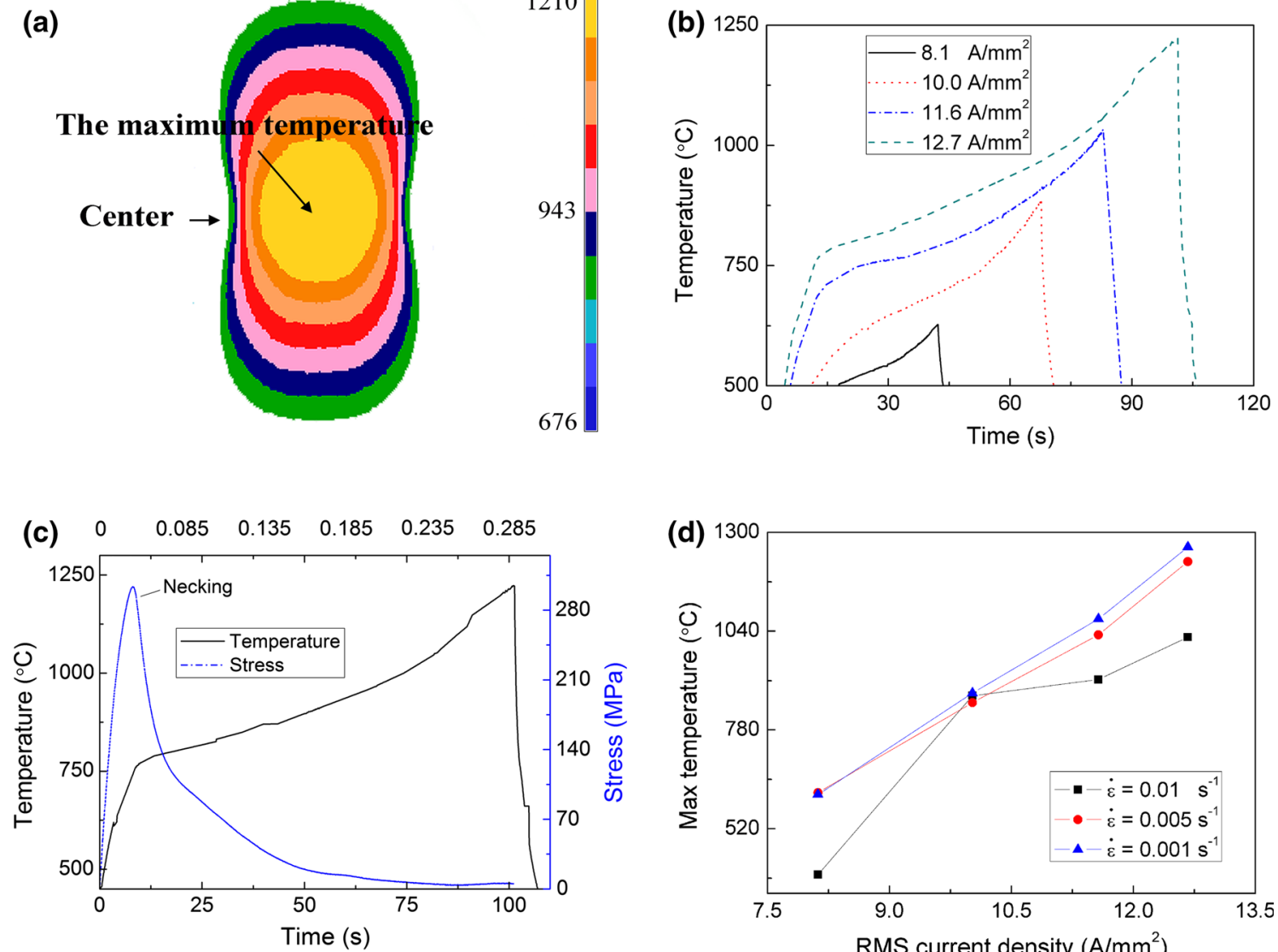

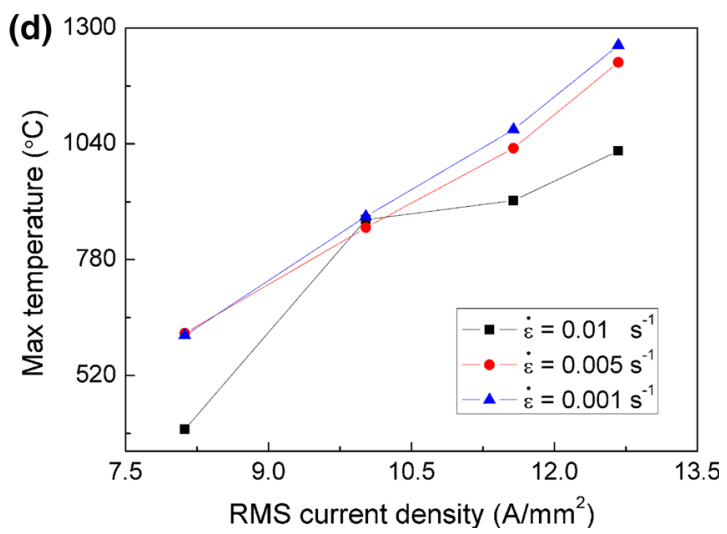

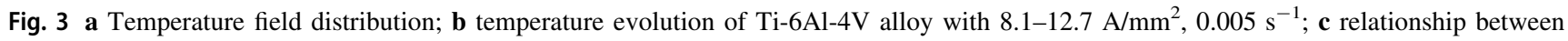
temperature curve and flow stress-strain curve; $\mathbf{d}$ the maximum temperature evolution under RMS current density and strain rates

where $\Delta T$ is temperature variation, $t$ is heating time, $I_{\mathrm{r}}$ is RMS current, $S$ is the initial cross-sectional area, $\gamma$ is resistivity, $C$ is specific heat, and $\rho$ is density of Ti-6Al-4V alloy.

\subsection{Stress-Strain Curves Under Electropulsing}

Figure 4 presents the mechanical behavior of Ti-6Al-4V alloy under RMS current density of $0-12.7 \mathrm{~A} / \mathrm{mm}^{2}$ and strain rates of $0.001-0.01 \mathrm{~s}^{-1}$. In Fig. 4a, the obvious strain hardening stage appears in uniform deformation stage below $8.1 \mathrm{~A} / \mathrm{mm}^{2}$. Strain hardening exponent $(n)$ calculated by Eq. (2) could describe uniform deformation ability [27]. Detailed variations of strain hardening exponent (n) under different RMS current density and strain rates are shown in Fig. 5a. As can be seen, the $n$ values decrease with the enhancement of RMS current density due to the electro-thermal softening effect. The balance between strain hardening and electro-thermal softening is much easier to obtain, decreasing the ultimate tensile strength as shown in Fig. 5b. As RMS current densities exceed 10.0 A/ $\mathrm{mm}^{2}$, the small $n$ values of (0.020-0.081) below $0.005 \mathrm{~s}^{-1}$ can be overlooked. The stress-strain curve presents a long necking stage in Fig. $4 \mathrm{a}, \mathrm{b}$. The strain rate sensitivity exponent $(m)$ value evaluated by Eq. (3) could represent the diffusion and transfer ability of necking after plastic instability, which can characterize the elongation to fracture [28]:

$n=\partial \ln \sigma /\left.\partial \ln \varepsilon\right|_{\dot{\varepsilon}, J_{\mathrm{r}}}$

Figure 5c presents the $m$ values evolution under RMS current density and strain rates. The smaller $m$ value (0.02) presents the low elongation to fracture (EL) at $8.1 \mathrm{~A} / \mathrm{mm}^{2}$. Under $12.7 \mathrm{~A} / \mathrm{mm}^{2}$ and $0.001 \mathrm{~s}^{-1}$, the $m>0.5$ and high elongation to fracture implies the superplastic characteristic, and the grain boundary sliding may become the primary plastic deformation mechanism. The EL varies nonmonotonically with the increase of RMS current density in Fig. 5d. Though decreasing at first, EL increases above $8.1 \mathrm{~A} / \mathrm{mm}^{2}$. Compared to cold tensile test (CT), the maximum EL is improved by $94.1 \%$ under $12.7 \mathrm{~A} / \mathrm{mm}^{2}$ and $0.001 \mathrm{~s}^{-1}$ :

$m=\partial \ln \sigma /\left.\partial \ln \dot{\varepsilon}\right|_{\varepsilon, J_{\mathrm{r}}}$ 

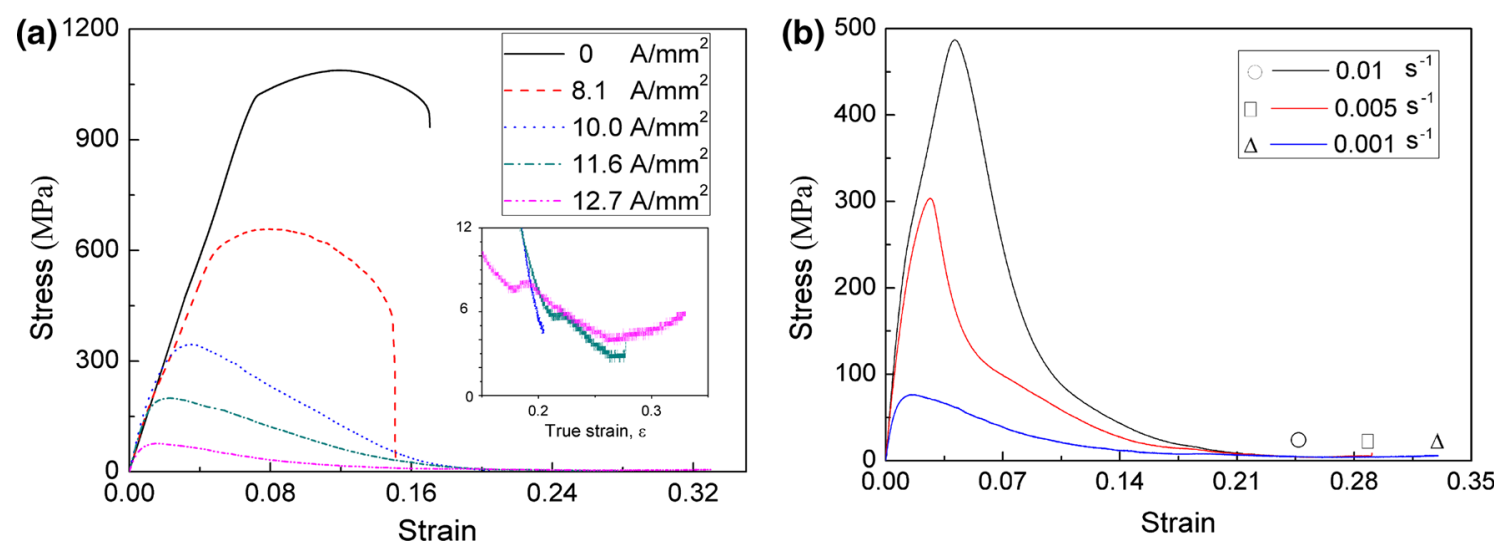

Fig. 4 Representative stress-strain curves under electropulsing: a $J_{\mathrm{r}}=0-12.7 \mathrm{~A} / \mathrm{mm}^{2}, J_{\mathrm{p}}=103.9 \mathrm{~A} / \mathrm{mm}^{2}, \varepsilon=0.001 \mathrm{~s}^{-1}, \mathbf{b} J_{\mathrm{r}}=12.7 \mathrm{~A} / \mathrm{mm}^{2}$, $J_{\mathrm{p}}=103.9 \mathrm{~A} / \mathrm{mm}^{2}, \dot{\varepsilon}=0.01-0.001 \mathrm{~s}^{-1}$
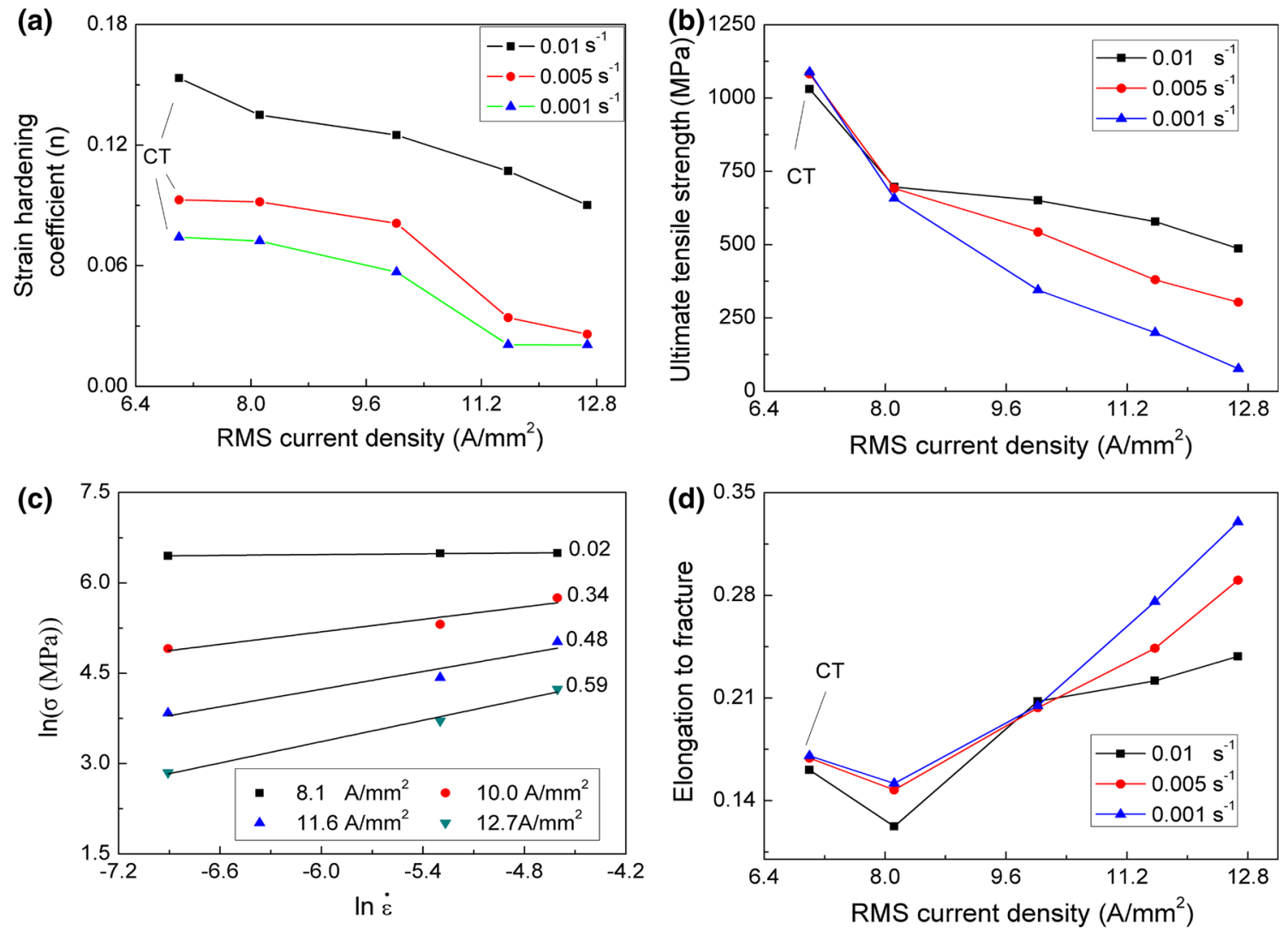

Fig. 5 a Variation of strain hardening exponent $n$; b ultimate tensile strength evolution under different RMS current densities and strain rates; c variation of strain rate sensitivity exponent $m$; d elongation to fracture under different RMS current densities and strain rates

The comparison of the temperature and flow stress results obtained with similar RMS current density but different peak current densities is shown in Fig. 6. By adjusting RMS current density, relative low temperature with high peak current density is obtained, as shown in Fig. 6(a).

As observed in Fig. 6(b), the flow stress under high peak current density is smaller than that under low peak current density with similar RMS current density. The more reduction of flow stress represents the higher EP effect. Hence, it can be concluded that the higher peak current density can lead to the more EP effect. Therefore, the EP effect of Ti-6Al-4V alloy can not only be regarded as a consequence of thermal effect. The athermal effect has a significant role in EP effect. 

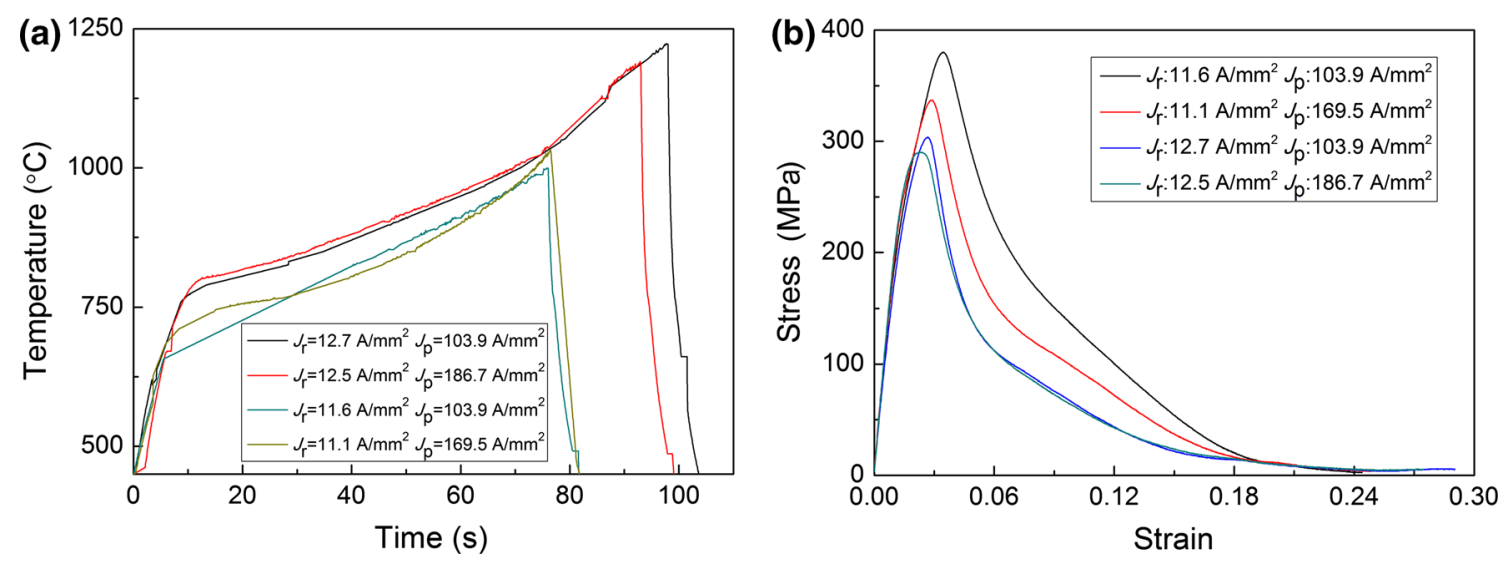

Fig. 6 a Temperature field of specimens with $J_{\mathrm{p}}=103.9-169.5 \mathrm{~A} / \mathrm{mm}^{2}$ at $J_{\mathrm{r}}=11.1-11.6 \mathrm{~A} / \mathrm{mm}^{2}, \quad J_{\mathrm{p}}=103.9-186.7 \mathrm{~A} / \mathrm{mm}^{2}$ at $J_{\mathrm{r}}=12.5-12.7 \mathrm{~A} / \mathrm{mm}^{2}$, b representative stress-strain curves corresponding to Fig. $6 \mathrm{a}, \mathrm{b}$ temperature field

\subsection{Microstructure Evolution}

Figure 7 presents XRD patterns at the fracture zone of Ti6Al-4V alloy subjected to RMS current density of $0-12.7 \mathrm{~A} / \mathrm{mm}^{2}$ at $0.001 \mathrm{~s}^{-1}$. The tensile specimens consist of $\alpha$ phase and $\beta$ phase. With increasing RMS current density, the $(110)_{\beta}$ peaks weaken gradually. This is indicated that the dissolution of $\beta$-Ti proceeds with increasing RMS current density.

Figure 8 shows the optical microstructure images of Ti$6 \mathrm{Al}-4 \mathrm{~V}$ alloy under RMS current density $(0,8.1,11.6$, and $\left.12.7 \mathrm{~A} / \mathrm{mm}^{-2}\right)$ and strain rates range $\left(0.001\right.$ and $\left.0.01 \mathrm{~s}^{-1}\right)$. A larger number of inclined elongation $\beta$ phase particle distribute in $\alpha$ phases, as shown in Fig. 8a. This phenomenon is caused by the $57^{\circ}$ angle between tensile direction and fracture surface, indicating that the microstructure is controlled by shear stress. At $8.1 \mathrm{~A} / \mathrm{mm}^{2}$, the $\beta$ phase begins to dissolve into $\alpha$ phases and the acicular $\beta$ phase forms, as shown in Fig. 8b. When the RMS

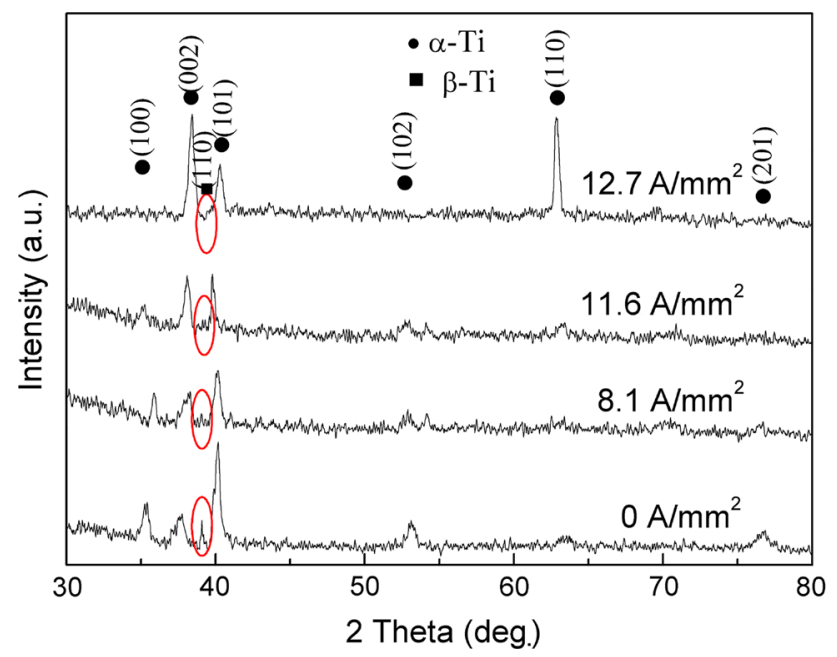

Fig. 7 XRD patterns for EPT specimens in fracture zone current density is increased to $11.6 \mathrm{~A} / \mathrm{mm}^{2}$, the volume fractions of $\beta$ phases decrease as the dissolution of $\beta$ phase proceeds in Fig. 8c. Different from the microstructures in the low current density, DRX takes place in $\alpha$ phase with the local average grain size of $5 \mu \mathrm{m}$ at $12.7 \mathrm{~A} / \mathrm{mm}^{2}$ in Fig. 8d.

Figure $8 b, d, e, f$ is the optical microstructure images in the fracture zone with the same RMS current density range of $8.1-12.7 \mathrm{~A} / \mathrm{mm}^{2}$ and different strain rate ranges of $0.001-0.01 \mathrm{~s}^{-1}$. More slightness $\beta$ phase was obtained at the lower strain rates. In addition, the corresponding volume percentages of $\beta$ phase are approximately the same with the percentages range from 14 to $15 \%$. It may be indicated that the $\beta$ phase did not change with the evolution of strain rates due to the low temperature under the small current density. Figure 8d, f presents obvious different microstructures with the strain rates of $0.001-0.01 \mathrm{~s}^{-1}$ at $12.7 \mathrm{~A} / \mathrm{mm}^{2}$. For the two conditions, the high temperatures are both obtained; there is sufficient time for the recrystallization under the lower strain rate of $0.001 \mathrm{~s}^{-1}$, being responsible for recrystallization structure in Fig. 8d, while no recrystallization structure was observed in Fig. $8 \mathrm{f}$ under the higher strain rate of $0.01 \mathrm{~s}^{-1}$.

\subsection{Fracture Morphology}

Figure 9 demonstrates the fracture morphology with RMS current density of $0-12.7 \mathrm{~A} / \mathrm{mm}^{2}$ and strain rates of $0.01-0.001 \mathrm{~s}^{-1}$. Figure 9a shows the fracture surface morphologies evolution with RMS current density under $0.001 \mathrm{~s}^{-1}$. As can be seen, the section shrinkage rates are almost the same below $8.1 \mathrm{~A} / \mathrm{mm}^{2}$. The section shrinkage rates enhance above $10.0 \mathrm{~A} / \mathrm{mm}^{2}$, which indicates that the plasticity is improved corresponding to Fig. 5d. From Fig. 9b, a lot of small size shear dimples and many tearing edges are distributed in the fracture surface, which shows a shearing dimple fracture characteristic. The dimples' shape 

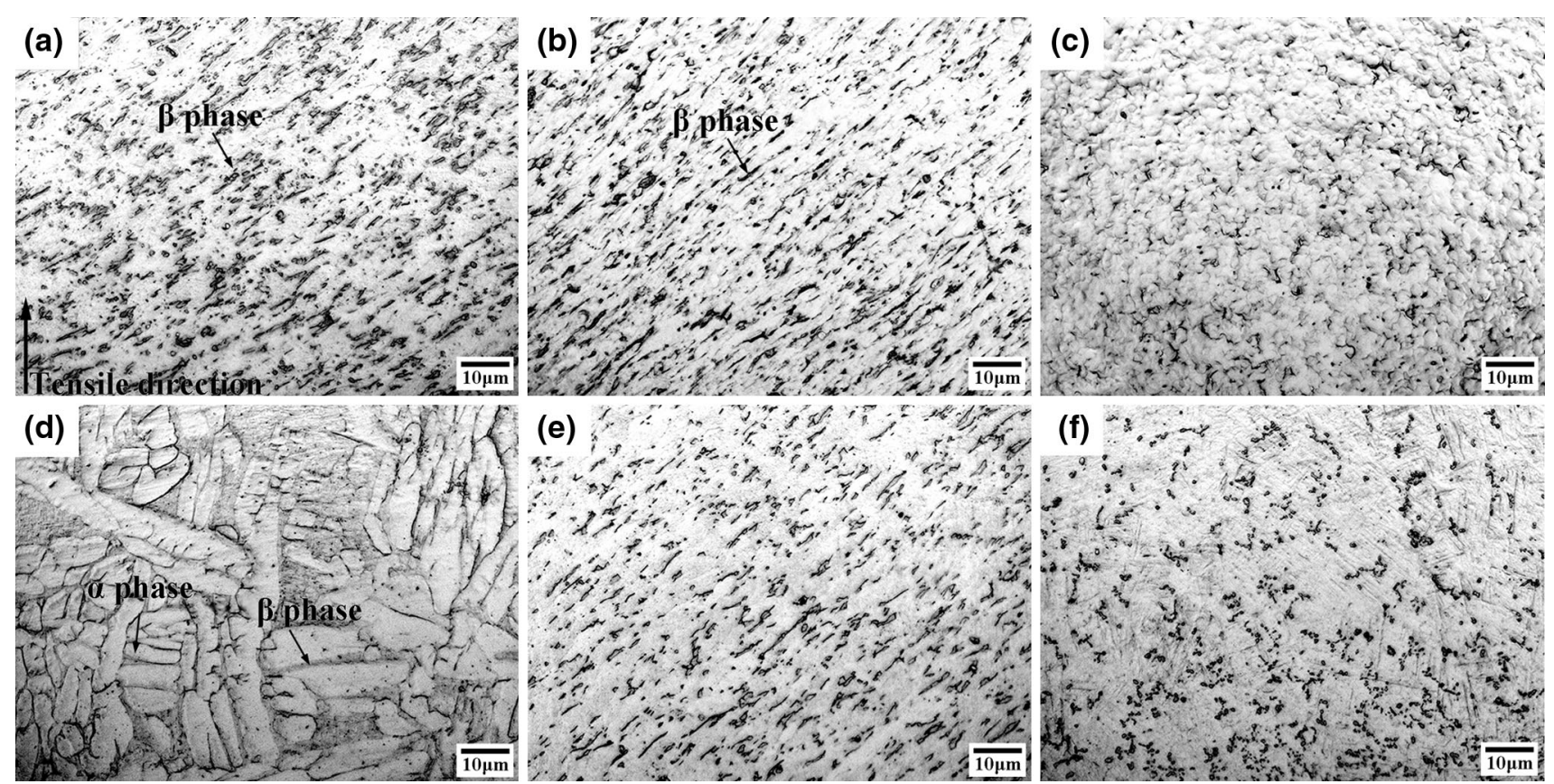

Fig. 8 Optical microstructure images of Ti-6Al-4V alloy under different RMS current densities and strain rates: a $0 \mathrm{~A} / \mathrm{mm}^{2}, 0.001 \mathrm{~s}{ }^{-1}, \mathbf{b} 8.1 \mathrm{~A} /$ $\mathrm{mm}^{2}, 0.001 \mathrm{~s}^{-1}, \mathbf{c} 11.6 \mathrm{~A} / \mathrm{mm}^{2}, 0.001 \mathrm{~s}^{-1}, \mathbf{d} 12.7 \mathrm{~A} / \mathrm{mm}^{2}, 0.001 \mathrm{~s}^{-1}, \mathbf{e} 8.1 \mathrm{~A} / \mathrm{mm}^{2}, 0.01 \mathrm{~s}^{-1}, \mathbf{f} 12.7 \mathrm{~A} / \mathrm{mm}^{2}, 0.01 \mathrm{~s}^{-1}$
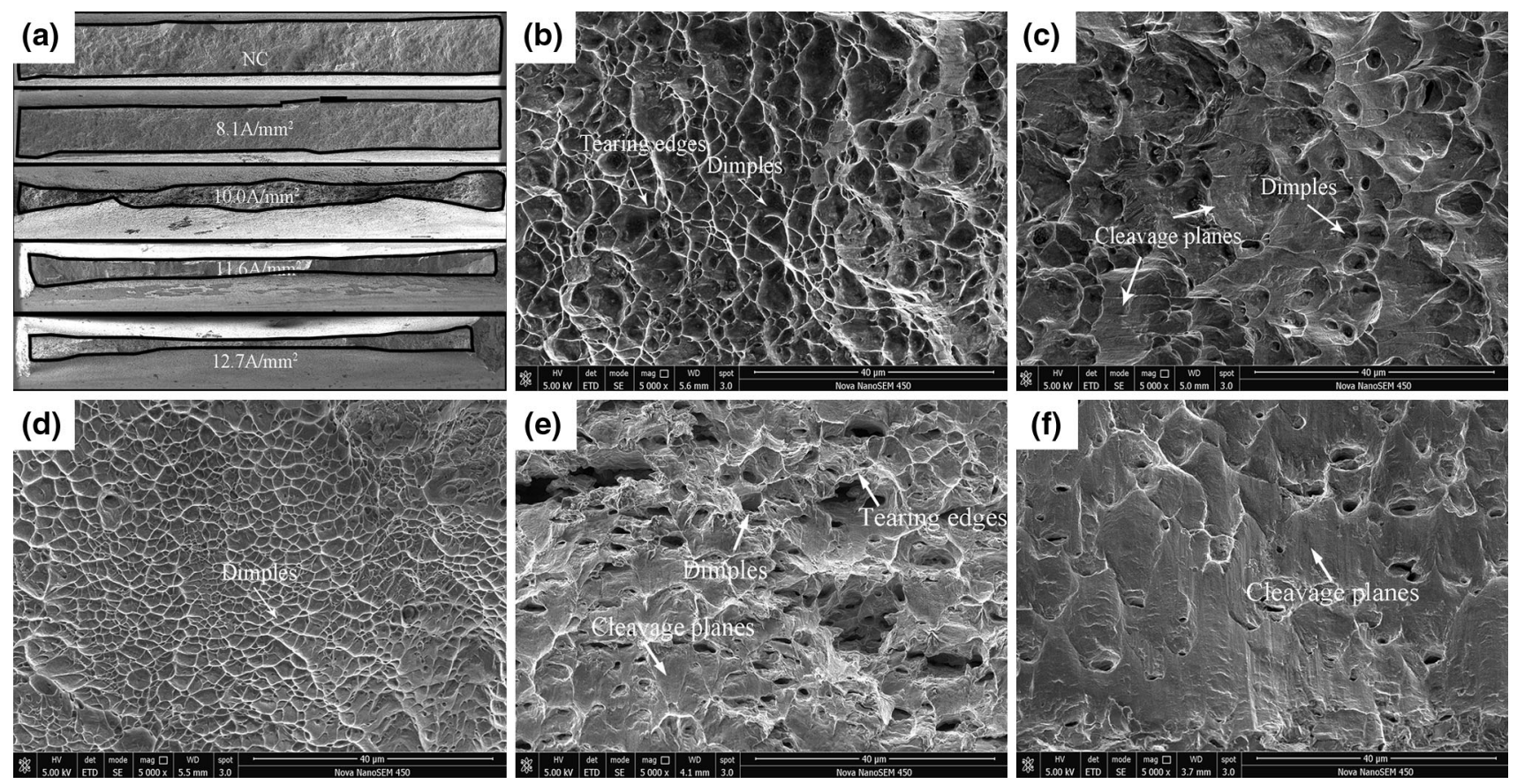

Fig. 9 Fracture morphology among a section shrinkage evolution under RMS current density and $0.001 \mathrm{~s}^{-1}$; b without current, $0.001 \mathrm{~s}^{-1}$, c $8.1 \mathrm{~A} / \mathrm{mm}^{2}, 0.001 \mathrm{~s}^{-1}, \mathbf{d} 11.6 \mathrm{~A} / \mathrm{mm}^{2}, 0.001 \mathrm{~s}^{-1}$, e $11.6 \mathrm{~A} / \mathrm{mm}^{2}, 0.005 \mathrm{~s}^{-1}$, f $11.6 \mathrm{~A} / \mathrm{mm}^{2}, 0.01 \mathrm{~s}^{-1}$

with a parabola and plenty of smooth cleavage planes are presented in Fig. 9c under $8.1 \mathrm{~A} / \mathrm{mm}^{2}$, showing tearing dimple characteristic. Figure 9d shows plenty of equiaxed dimples at $11.6 \mathrm{~A} / \mathrm{mm}^{2}$. The micro-void coalescence is the main fracture characteristic. The fracture morphology varies with RMS current density from shearing dimple, tearing dimple to equiaxed dimple at $0.001 \mathrm{~s}^{-1}$.

Figure $9 \mathrm{~d}-\mathrm{f}$ presents the fracture morphology under $11.6 \mathrm{~A} / \mathrm{mm}^{2}$ and strain rates of $0.001,0.005$, and $0.01 \mathrm{~s}^{-1}$, respectively. With increasing strain rates, small cleavage planes, micro-voids, and tearing edges appear in Fig. 9e. 
The fracture mode becomes quasi-cleavage fracture. Plenty of cleavage planes are shown in Fig. 9f, which indicates the cleavage fracture. As the strain rates change, the fracture mode changes from dimple fracture, quasi-cleavage fracture, to cleavage fracture at $11.5 \mathrm{~A} / \mathrm{mm}^{2}$.

\section{Discussion}

\subsection{Effect of Electropulsing on Microstructure Evolution}

Based on the above experimental results, it is found that the thermal and athermal effects of electropulsing can promote the dissolution of $\beta$ phase and recrystallization of Ti-6Al$4 \mathrm{~V}$ alloy. The mechanism of EP effect is sophisticated due to the existence of athermal effect. One possible mechanism is that EP effect can affect the thermodynamics and kinetics of Ti-6Al-4V alloy.

\subsubsection{Effect of Electropulsing on Dissolution of $\beta$ Phase}

The dissolution of $\beta$ phase takes place when kinetics and thermodynamic are both satisfied. On one hand, analysis from kinetics and dissolution of $\beta$ phase depends on the diffusion of $\mathrm{V}$ atom in Ti-6Al-4V alloy under electropulsing. The athermal effect could accelerate the flux of diffusing atom [20], which contributes to the dissolution of $\beta$ phase. On the other hand, electropulsing could decrease thermodynamic barrier of the $\beta \rightarrow \alpha$ phase transformation [29]. Thus, the dissolution of $\beta$ phase particles is obtained under electropulsing-assisted tensile process.

\subsubsection{Effect of Electropulsing on Recrystallization}

Recrystallization is related with the dislocation climbing into subgrain boundaries. According to the kinetic analysis, the large flux of diffusing atom induced by athermal effect can promote dislocation climbing process [30], accelerating the recrystallization of Ti-6Al-4V alloy.

Under $12.7 \mathrm{~A} / \mathrm{mm}^{2}$ and $0.001 \mathrm{~s}^{-1}$, DRX occurs in superplastic deformation. Recrystallization is the process of grain boundary diffusion and migration [27]. Electropulsing accelerates grain boundary diffusion and migration, which could promote $\alpha$ grain boundary sliding [31]. In addition, the streamline morphology of $\beta$ phase around some recrystallized $\alpha$ grain is observed in Fig. $8 \mathrm{~d}$. Since $\beta$ phases as plastic phases with body-centered cubic deforms more easily than $\alpha$ phase with hexagonal closepacked under high temperature, deformed $\beta$ phases can act as lubricant for $\alpha$ grain boundary sliding, making grain boundary sliding operational. Consequently, $\alpha$ grain boundary sliding may be the main deformation mechanism at $12.7 \mathrm{~A} / \mathrm{mm}^{2}$ and $0.001 \mathrm{~s}^{-1}$.

\subsection{Effect of Electropulsing and Microstructure on Mechanical Properties}

The experimental results present that the flow stress decreases with the enhancement of RMS current density. In addition to electro-thermal softening effect, the $\beta$ phase particle spacing could affect the flow stress. As shown in Fig. 10, the $\beta$ phase particle spacing increases with RMS current density. Based on Orowan model in Eq. (4) [32], the increase of $\beta$ particle spacing can make dislocation bypass easily, which contributes to the decrease of flow stress.

$\sigma=G b / L$,

where $\sigma$ is Orowan stress, $G$ is shear modulus of the matrix, $b$ is Burges vector of the dislocation, and $L$ is $\beta$ particle spacing.

The coarse $\beta$ phase particle can efficiently pin up dislocation and hind the dislocation movement during cold tensile. Meanwhile, because of the less non-basal slip in matrix $\alpha$ phase and the strong 0001 basal texture [19], the cold tensile specimens generally express poor plasticity, as shown in Fig. 5d. The volume fracture of $\beta$ phase decreases with the enhancement of RMS current density in Fig. 10, which is in according with the microstructure evolution as presented in Fig. 8. The dissolution of $\beta$ phases could reduce the $\alpha-\beta$ interface and decrease the dislocation movement resistance [33], which contributes to the enhancement of plasticity. However, for the case with $8.1 \mathrm{~A} / \mathrm{mm}^{2}$, the deterioration of plasticity can be seen in Fig. 5d. The causes of the phenomenon are analyzed as follows. From the fracture morphology at $8.1 \mathrm{~A} / \mathrm{mm}^{2}$, as shown in Fig. 11, it can be seen that $\beta$ phase locates at the

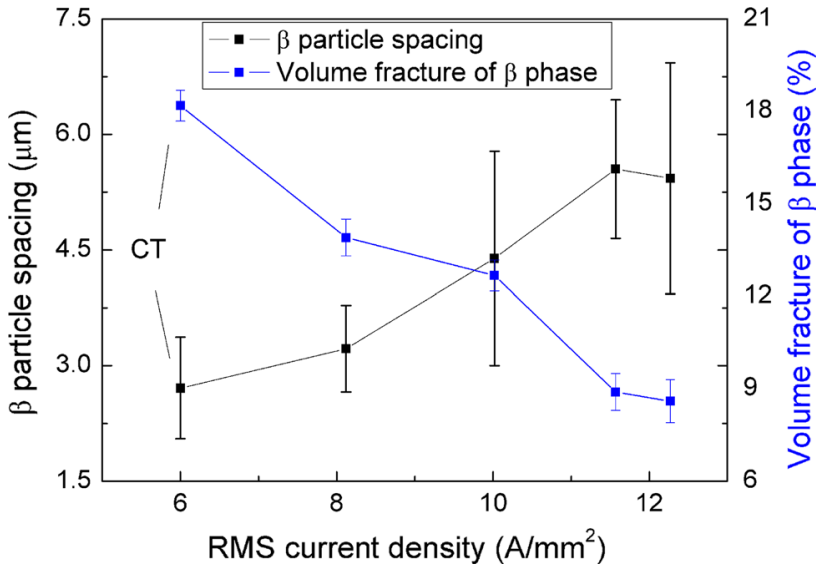

Fig. 10 Dependencies of volume fracture of $\beta$ phase and $\beta$ particle spacing on RMS current density 

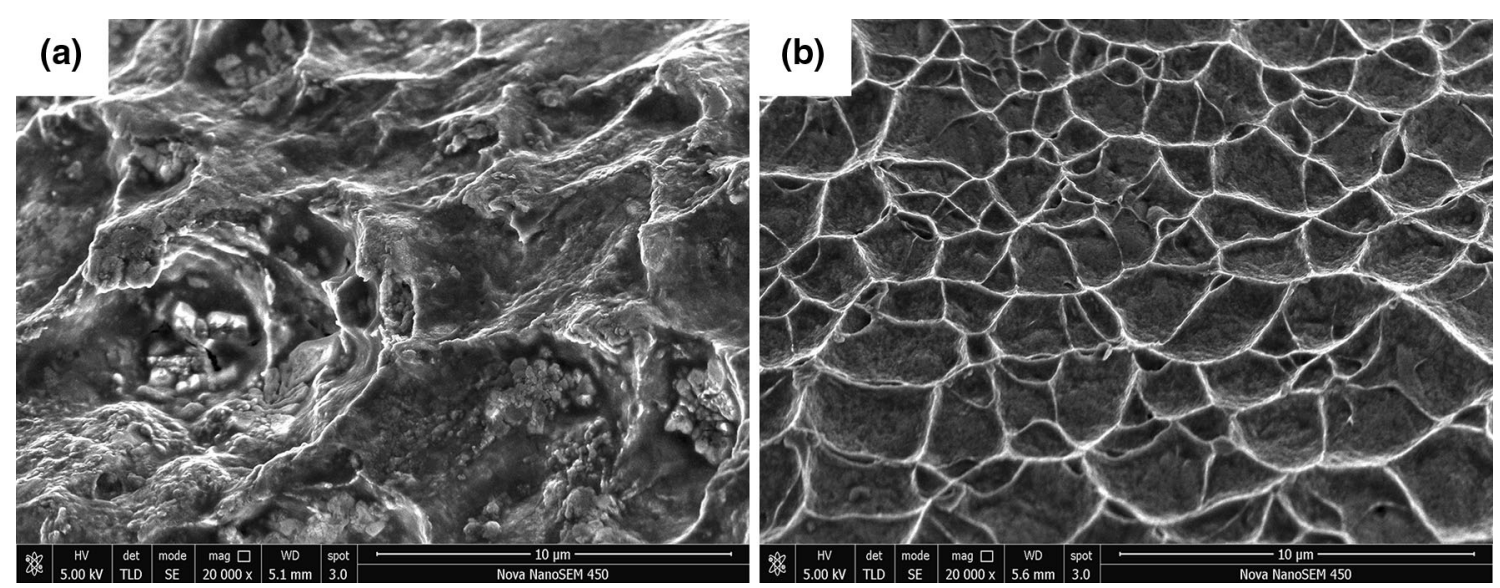

Fig. 11 Fracture morphologies under a $8.1 \mathrm{~A} / \mathrm{mm}^{2}, 0.001 \mathrm{~s}^{-1}$; b $11.5 \mathrm{~A} / \mathrm{mm}^{2}, 0.001 \mathrm{~s}^{-1}$

bottom of dimples, which are regarded as the nucleation center of voids. Moreover, dynamic recovery can make tilted elongation $\beta$ phases turn into acicular phases at $8.1 \mathrm{~A} / \mathrm{mm}^{2}$. The stress concentration is easy to occur at the tips of acicular $\beta$ phases. As the concentrated stress exceeds the interfacial strength of $\alpha-\beta$ phase, micro-voids are prone to nucleation and growth at the tips of $\beta$ phase. It could lead to the rapid premature fracture, contributing to the low elongation at $8.1 \mathrm{~A} / \mathrm{mm}^{2}$. Accompanied by the dissolution of $\beta$ phases at high current density, there are no much $\beta$ phases at the bottom of dimples in Fig. 10b. It decreases the possible of rapid premature fracture. Furthermore, electropulsing inclines to weaken basal texture and promote the non-basal slip [30], and thus, the plasticity of Ti-6Al-4V alloy can be improved.

\section{Conclusions}

(1) Tensile strength decreases with increasing current density. The tensile elongation decreases first and then increases with current density once the density value exceeds $8.1 \mathrm{~A} / \mathrm{mm}^{2}$. Micro-voids nucleate and grow more easily at the tips of acicular $\beta$ phases, causing the low elongation to fracture at $8.12 \mathrm{~A} /$ $\mathrm{mm}^{2}$.

(2) Electropulsing can promote the dissolution of $\beta$ phase and DRX of $\alpha$ phase, which contributes to the enhancement of plasticity. The maximum elongation is improved by $94.1 \%$ under $12.7 \mathrm{~A} / \mathrm{mm}^{2}$ and $0.001 \mathrm{~s}^{-1}$.

(3) The electropulsing with higher peak current density has the larger electroplastic effect, and the athermal effect of electropulsing of Ti-6Al-4V alloy is proved to exist.
Acknowledgements This work is supported by the Natural Science Foundation of Shandong Province (No. ZR2016EEM25).

\section{References}

[1] F.H. Li, X.H. Yi, J.L. Zhang, Z.G. Fan, D.T. Gong, Z.P. Xi, Acta Metall. Sin. (Engl. Lett.) 23, 293 (2010)

[2] G.L. Ma, Y.H. Lu, C. Zhu, Acta Metall. Sin. (Engl. Lett.) 13, 665 (2000)

[3] S.D. Ji, A.L. Zhou, Y.M. Yue, G.H. Luan, Y.Y. Jin, F. Li, Acta Metall. Sin. (Engl. Lett.) 25, 365 (2012)

[4] P. Guo, Y. Zhao, W. Zeng, Q. Hong, Mater. Sci. Eng., A 563, 106 (2013)

[5] M.J. Kim, K. Lee, K.H. Oh, I.S. Choi, H.H. Yu, S.T. Hong, H.N. Han, Scripta Mater. 75, 58 (2014)

[6] J.H. Roh, J.J. Seo, S.T. Hong, M.J. Kim, H.N. Han, J.T. Rorh, Int. J. Plast. 58, 84 (2014)

[7] X. Ye, X. Li, G. Song, G. Tang, J. Alloys Compd. 616, 173 (2014)

[8] Y. Zhou, G.Q. Chen, X.S. Fu, W.L. Zhou, Trans. Nonferrous Metals Soc. China 24, 1012 (2014)

[9] X. Li, B. Ji, Q. Zhou, J. Chen, P. Gao, J. Mater. Eng. Perform. 25, 4514 (2016)

[10] H. Song, Z.J. Wang, T.J. Gao, Trans. Nonferrous Metals Soc. China 17, 87 (2007)

[11] K. Okazaki, M. Kagawa, H. Conrad, Scripta Mater. 12, 1063 (1978)

[12] K. Okazaki, M. Kagawa, H. Conrad, Scripta Mater. 13, 473 (1979)

[13] O.A. Troitskii, V.I. Likhtman, Soviet Phys. Doklady 8, 332 (1963)

[14] O.A. Troitskii, Strength Mater. 9, 35 (1977)

[15] O.A. Troitskii, Strength Mater. 16, 277 (1984)

[16] H. Conrad, Mater. Sci. Eng., A 287, 227 (2000)

[17] K. Okazaki, K. Kagawa, H. Conrad, Mater. Sci. Eng. 45, 109 (1980)

[18] L. Guan, G. Tang, P.K. Chu, J. Mater. Res. 25, 1215 (2011)

[19] X. Ye, G. Tang, G. Song, J. Kuang, J. Mater. Res. 29, 1500 (2014)

[20] X. Ye, Z.T.H. Tse, G. Tang, J. Mater. Res. 30, 206 (2014)

[21] H. Xie, X. Dong, K. Liu, Z. Ai, F. Peng, Q. Wang, F. Chen, J. Wang, Mater. Sci. Eng., A 637, 23 (2015)

[22] B. Kinsey, G. Cullen, A. Jordan, S. Mates, CIRP Ann. Manuf. Technol. 62, 279 (2013) 
[23] J. Magargee, F. Morestin, J. Cao, J. Eng. Mater. Technol. 135, 041003 (2013)

[24] X. Wang, J. Xu, D. Shan, B. Guo, J. Cao, Mater. Des. 127, 134 (2017)

[25] X. Wang, J. Xu, Z. Jiang, W.L. Zhu, D. Shan, B. Guo, J. Cao, Mater. Sci. Eng., A 659, 215 (2016)

[26] W. Bao, X. Chu, S. Lin, J. Gao, Mater. Sci. Technol. 33, 1 (2016)

[27] J. Deng, Y.C. Lin, S.S. Li, J. Chen, Y. Ding, Mater. Des. 49, 209 (2013)
[28] J. Luo, M. Li, W. Yu, H. Li, Mater. Des. 31, 741 (2010)

[29] X. Ye, J. Kuang, X. Li, G. Tang, J. Alloys Compd. 599, 1 (2014)

[30] X. Ye, Z.T.H. Tse, G. Tang, G. Song, Mater. Charact. 98, 147 (2014)

[31] X. Ye, Z.T.H. Tse, G. Tang, X. Li, G. Song, J. Mater. Process. Technol. 222, 27 (2015)

[32] S.O. Ojediran, O. Ajaja, J. Mater. Sci. 23, 4037 (1988)

[33] W.F. Cui, Z. Jin, A.H. Guo, L. Zhou, Mater. Sci. Eng., A 499, 252 (2009) 